\title{
A Novel Functionally Distinct Subtype of Striatal Neuropeptide Y Interneuron
}

\author{
Osvaldo Ibáñez-Sandoval, Fatuel Tecuapetla, Bengi Unal, Fulva Shah, Tibor Koós, and James M. Tepper \\ Center for Molecular and Behavioral Neuroscience, Rutgers University, Newark, New Jersey 07102
}

We investigated the properties of neostriatal neuropeptide Y (NPY)-expressing interneurons in transgenic GFP (green fluorescent protein)-NPY reporter mice. In vitro whole-cell recordings and biocytin staining demonstrated the existence of a novel class of neostriatal NPY-expressing GABAergic interneurons that exhibit electrophysiological, neurochemical, and morphological properties strikingly different from those of previously described NPY-containing, plateau-depolarization low-threshold spike (NPY-PLTS) interneurons. The novel NPY interneuron type (NPY-neurogliaform) differed from previously described NPY-PLTS interneurons by exhibiting a significantly lower input resistance and hyperpolarized membrane potential, regular, nonaccommodating spiking in response to depolarizing current injections, and an absence of plateau depolarizations or low-threshold spikes. NPY-neurogliaform interneurons were also easily distinguished morphologically by their dense, compact, and highly branched dendritic and local axonal arborizations that contrasted sharply with the sparse and extended axonal and dendritic arborizations of NPY-PLTS interneurons. Furthermore, NPYneurogliaform interneurons did not express immunofluorescence for somatostatin or nitric oxide synthase that was ubiquitous in NPY-PLTS interneurons. IPSP/Cs could only rarely be elicited in spiny projection neurons (SPNs) in paired recordings with NPY-PLTS interneurons. In contrast, the probability of SPN innervation by NPY-neurogliaform interneurons was extremely high, the synapse very reliable (no failures were observed), and the resulting postsynaptic response was a slow, $\mathrm{GABA}_{\mathrm{A}}$ receptor-mediated IPSC that has not been previously described in striatum but that has been elicited from NPY-GABAergic neurogliaform interneurons in cortex and hippocampus. These properties suggest unique and distinctive roles for NPY-PLTS and NPY-neurogliaform interneurons in the integrative properties of the neostriatum.

\section{Introduction}

The neostriatum is composed almost entirely of GABAergic neurons. The vast majority of these are the spiny projection neurons (SPNs) that make up $\sim 95 \%$ of the rodent striatum (Graveland and DiFiglia, 1985; Gerfen and Wilson, 1996). The remaining neurons consist of cholinergic interneurons, and several different subtypes of GABAergic interneurons that have been classified and parsed electrophysiologically, morphologically, and/or neurochemically (Kawaguchi, 1993; Kawaguchi et al., 1995; Wu and Parent, 2000; Tepper and Bolam, 2004; Ibáñez-Sandoval et al., 2010; Tepper et al., 2010). These interneurons play crucial roles in striatal functioning. While cholinergic interneurons exert critically important neuromodulatory effects on SPNs (Nishi et al., 1990; Kitai and Surmeier, 1993; Calabresi et al., 2000), GABAer-

\footnotetext{
Received May 25, 2011; revised Sept. 20, 2011; accepted Sept. 21, 2011.

Author contributions: 0.I.-S., T.K. and J.M.T. designed research; 0.I.-S., F.T., B.U., F.S., and T.K. performed research; 0.I.-S., F.T., B.U., T.K., and J.M.T. analyzed data; 0.I.-S., B.U., T.K., and J.M.T. wrote the paper.

This work was supported, in part, by NIH Grants NS034865 (J.M.T.), NS052370 (T.K.), and NS072950 (T.K., J.M.T.), and Rutgers University. We thank Dr. Elizabeth D. Abercrombie for generously allowing us the use of her microscopes and image acquisition and analysis software, Ruthy Sher for assistance with cell drawings, and Dr. Anatol Kreitzer for helpful discussions.

Correspondence should be addressed to Dr. James M. Tepper, Center for Molecular and Behavioral Neuroscience, Rutgers, The State University of New Jersey, 197 University Avenue, Newark, NJ 07102. E-mail: jtepper@andromeda.rutgers.edu.

F. Tecuapetla's present address: Neurobiology of Action, Instituto Gulbenkian de Ciencia, Rua da Quinta Grande, 6, 2780-156 0eiras, Portugal.

DOI:10.1523/JNEUROSCI.2628-11.2011

Copyright $\odot 2011$ the authors $\quad 0270-6474 / 11 / 3116757-13 \$ 15.00 / 0$
}

gic interneurons, including fast-spiking interneurons (FSIs) and low threshold-spiking (LTS) interneurons, have been shown to exert powerful, fast feedforward inhibitory effects on SPNs (Koós and Tepper, 1999; Koós et al., 2004; Tepper et al., 2004, 2008; Taverna et al., 2007; Gittis et al., 2010).

Classically, three different subtypes of neostriatal GABAergic interneurons have been distinguished neurochemically. These include FSIs that express the calcium-binding protein, parvalbumin (PV), an electrophysiologically unidentified interneuron that expresses the calcium binding protein, CR (calretinin), and a third interneuron that exhibits both low-threshold spiking and plateau potentials (PLTS) that coexpresses neuropeptide $\mathrm{Y}$ (NPY), somatostatin (SOM), and nitric oxide synthase (NOS) (Kawaguchi, 1993; Kawaguchi et al., 1995). Recently, using a transgenic mouse that expresses EGFP (enhanced green fluorescent protein) under the control of the regulatory sequences of the tyrosine hydroxylase (TH) gene, we described four additional, electrophysiologically distinct striatal $\mathrm{TH}^{+}$interneurons that comprise a fourth main class of striatal GABAergic interneurons (Ibáñez-Sandoval et al., 2010).

It was originally assumed that the striatal GABAergic interneurons that are immunopositive for NPY form a single population of GABAergic interneurons that coexpress the peptides SOM and NOS and exhibit the electrophysiological phenotype of the PLTS cell (Kawaguchi, 1993; Kawaguchi et al., 1995; Kubota and Kawaguchi, 2000). However, Figueredo-Cardenas et al. (1996) found that $\sim 25 \%$ of the neurons expressing SOM and 
NOS were not immunopositive for NPY. Those data demonstrated that striatal SOM/NOS/NPY interneurons are neurochemically heterogeneous and also suggest the possibility that they might be electrophysiologically and/or morphologically heterogeneous as well. We tested this idea by visualizing striatal NPY interneurons in brain slices from transgenic mice that express GFP under the control of endogenous NPY transcription factors and obtaining whole-cell recordings, staining the neurons with biocytin, and performing NPY, SOM, and NOS immunocytochemistry. The results indicated that there are two electrophysiologically, morphologically, and neurochemically distinct subtypes of GFP-NPY ${ }^{+}$interneurons, one of which has not been previously described.

\section{Materials and Methods}

Subjects. Subjects were adult (2-3 months of age) bacterial artificial chromosome (BAC) transgenic mice of both sexes that express the humanized Renilla green fluorescent protein (hrGFP) (Stratagene) under the control of the mouse NPY promoter (stock 006417; The Jackson Laboratory). Hemizygous transgenic mice were obtained from The Jackson Laboratory and mated to C57BL/6 mice in our animal colony at Rutgers-Newark. Offspring were genotyped and those found to be heterozygous positive for the transgene were used for all recordings. All procedures were performed with the approval of the Rutgers University Institutional Animal Care and Use Committee and in accordance with the NIH Guide to the Care and Use of Laboratory Animals.

Preparation of brain slices. Mice were deeply anesthetized with 150 $\mathrm{mg} / \mathrm{kg}$ ketamine and $30 \mathrm{mg} / \mathrm{kg}$ xylazine intraperitoneally and transcardially perfused with ice-cold, modified Ringer's solution containing $248 \mathrm{~mm}$ sucrose, $2.5 \mathrm{~mm} \mathrm{KCl}, 7 \mathrm{~mm} \mathrm{MgCl}$, $23 \mathrm{~mm} \mathrm{NaHCO}, 1.2 \mathrm{~mm}$ $\mathrm{NaH}_{2} \mathrm{PO}_{4}, 7 \mathrm{~mm}$ glucose, $1 \mathrm{~mm}$ ascorbate, $3 \mathrm{~mm}$ pyruvate, and bubbled with $95 \% \mathrm{O}_{2}$ and $5 \% \mathrm{CO}_{2}, \mathrm{pH}$ 7.3. After decapitation, the brain was quickly removed into a beaker containing ice-cold oxygenated Ringer's and trimmed to a block containing the striatum. Coronal or oblique parahorizontal sections, $300 \mu \mathrm{m}$ in thickness, were cut in the same medium using a Vibratome 3000 and immediately transferred to normal Ringer's solution containing $124 \mathrm{~mm} \mathrm{NaCl}, 2.5 \mathrm{~mm} \mathrm{KCl}, 1.2 \mathrm{~mm}$ $\mathrm{NaH}_{2} \mathrm{PO}_{4}, 26 \mathrm{~mm} \mathrm{NaHCO}_{3}, 1.3 \mathrm{~mm} \mathrm{MgCl} 2,2 \mathrm{~mm} \mathrm{CaCl}_{2}, 10 \mathrm{~mm}$ glucose, $1 \mathrm{~mm}$ ascorbate, $3 \mathrm{~mm}$ pyruvate, and $0.4 \mathrm{~mm}$ myo-inositol, which was heated to $34^{\circ} \mathrm{C}$ and continuously bubbled with $95 \% \mathrm{O}_{2}$ and $5 \% \mathrm{CO}_{2}, \mathrm{pH}$ 7.3 , for $1 \mathrm{~h}$ before recording and thereafter maintained at room temperature until use. Slices were transferred to the recording chamber and submerged in continuously flowing oxygenated buffer $(2-4 \mathrm{ml} / \mathrm{min})$, which was heated to $\sim 34^{\circ} \mathrm{C}$.

Fluorescence and differential interference contrast imaging and recording. Slices were initially visualized under epifluorescence illumination with a high-sensitivity digital frame transfer camera (Cooke SensiCam) mounted on an Olympus BX50-WI epifluorescence microscope with a $40 \times$ long working distance water-immersion lens. Once a $\mathrm{GFP}^{+}$interneuron was identified, visualization was switched to infrared-differential interference contrast microscopy for the actual patching of the neuron. Micropipettes for whole-cell recording were constructed from $1.2 \mathrm{~mm}$ outer diameter borosilicate pipettes on a Narishige PP- 83 vertical puller. The standard internal solution for whole-cell current-clamp recording was as follows (in $\mathrm{mm}$ ): $130 \mathrm{~K}$-gluconate, $10 \mathrm{NaCl}, 2 \mathrm{MgCl}_{2}, 10$ HEPES, $3 \mathrm{Na}_{2} \mathrm{ATP}$, $0.3 \mathrm{GTP}, 1 \mathrm{EGTA}, 0.1 \mathrm{CaCl}_{2}$ plus $0.1-0.3 \%$ biocytin, $\mathrm{pH}$ 7.3-7.4. In some voltage-clamp experiments, the K-gluconate was replaced by 134 or $140 \mathrm{~mm} \mathrm{CsCl}$ (see Results) or $140 \mathrm{~mm} \mathrm{CsMeSO}_{4}$. These pipettes had a DC impedance of 4-6 M $\Omega$. All membrane potentials were corrected for a tip potential of $13 \mathrm{mV}$. In some cases, to visualize the recorded neuron during the experiment, the internal solution contained $25 \mu \mathrm{M}$ Alexa Fluor 594 (Invitrogen).

Whole-cell current-clamp recordings were made with a Neurodata IR-283 current-clamp amplifier and voltage-clamp recordings were obtained with a Molecular Devices Multiclamp 700B. Recordings were digitized at $20-40 \mathrm{kHz}$ with a CED Micro $1401 \mathrm{Mk}$ II and a PC running Signal, version 5 (Cambridge Electronic Design).
At the completion of the experiments, slices containing biocytininjected neurons were fixed by immersion in $4 \%$ paraformaldehyde$0.5 \%$ glutaraldehyde for $30 \mathrm{~min}$ at room temperature or microwaved in that fixative solution to $60^{\circ} \mathrm{C}$ for $10 \mathrm{~s}$ and stored overnight in PBS at $4^{\circ} \mathrm{C}$.

Cortical stimulation. Stimulating electrodes consisted of concentric bipolar electrodes, with tip diameter of $25 \mu \mathrm{m}$, with $1 \mathrm{k} \Omega$ DC resistance (FHC). Electrodes were placed at the border of the primary and secondary motor cortices [according to the atlas of Franklin and Paxinos (2008)] in coronal slices. Stimuli consisted of single square wave pulses (typically $0.01-1 \mathrm{~mA}, 0.1-0.2 \mathrm{~ms}$ duration at $0.1 \mathrm{~Hz}$ ) and were generated by a Winston A- 65 timer and SC- 100 constant-current stimulus isolation unit.

Biocytin histochemistry. In some cases, the $300 \mu \mathrm{m}$ sections were resectioned on a Vibratome at $60 \mu \mathrm{m}$. Sections were washed three times for 10 min each in $0.1 \mathrm{M}$ phosphate buffer (PB) followed by $10 \%$ methanol and $3 \% \mathrm{H}_{2} \mathrm{O}_{2}$ for $15 \mathrm{~min}$ After three washes for $10 \mathrm{~min}$ each in $0.1 \mathrm{M}$ PBS, the sections were incubated with avidin-biotin peroxidase complex (Vector Laboratories; $1: 200)$ and $0.1 \%$ Triton X-100 overnight at $4^{\circ} \mathrm{C}$. After washing six times for $10 \mathrm{~min}$ each in $0.1 \mathrm{M} \mathrm{PB}$, the sections were reacted with $3,3^{\prime}$-diaminobenzidine (DAB) $(0.025 \%)$ and $\mathrm{H}_{2} \mathrm{O}_{2}(0.0008 \%)$ in PB. In some cases, nickel intensification was used ( $2.5 \mathrm{~mm}$ nickel ammonium sulfate and $7 \mathrm{~mm}$ ammonium chloride in the $\mathrm{DAB}$ and $\mathrm{H}_{2} \mathrm{O}_{2}$ incubation). The sections were then postfixed in osmium tetroxide $(0.1 \%$ in $\mathrm{PB}$ ) for $30 \mathrm{~min}$, dehydrated through a graded series of ethanol, followed by propylene oxide, and infiltrated overnight with a mixture of propylene oxide and epoxy resin (Durcupan; Fluka Chemie). The sections were then transferred to fresh resin mixture for several hours and flatembedded between glass slides and coverslips and cured at $60^{\circ} \mathrm{C}$ for $24 \mathrm{~h}$.

Immunocytochemistry. To ascertain the colocalization of NPY, SOM, and NOS, an overdose of ketamine/xylazine was administered, and mice were perfused transcardially with ice-cold Ringer's buffer followed by $4 \%$ paraformaldehyde and $15 \%$ picric acid in $0.1 \mathrm{M} \mathrm{NaH}_{2} \mathrm{PO}_{4}$ buffer, $\mathrm{pH}$ 7.4. Mice were decapitated, and the brains were removed and left in the same fixative overnight at $4^{\circ} \mathrm{C}$ before sectioning on a Vibratome at $60 \mu \mathrm{m}$. In a few cases, the following procedure was also performed on sections containing electrophysiologically identified neurons filled with biocytin. Sections destined for NPY and SOM immunocytochemistry were pretreated with $1 \%$ sodium borohydride followed by $10 \%$ methanol and $3 \%$ $\mathrm{H}_{2} \mathrm{O}_{2}$ in PBS, whereas sections used for NOS immunocytochemistry were pretreated with $0.1 \mathrm{M}$ glycine in PBS for $15 \mathrm{~min}$ before incubation in $10 \%$ normal donkey serum (NDS), 3\% bovine serum albumin (BSA), and $0.5 \%$ Triton $\mathrm{X}-100$ for $4-5 \mathrm{~h}$ at room temperature. Sections were then incubated in polyclonal antibody against NPY (1:1000; rabbit antineuropeptide Y; ImmunoStar; 22940), SOM (1:1000; rabbit anti-somatostatin; ImmunoStar; 20067), or NOS (1:1000; goat anti-neuronal nitric oxide synthase; Abcam; Ab1376) diluted in a solution containing 1\% NDS, $1 \%$ BSA, and $0.1 \%$ Triton X-100 in PBS for $31 \mathrm{~h}$ at room temperature. After washing three times for 10 min each in PBS, sections for NPY or SOM immunocytochemistry were incubated in donkey anti-rabbit IgG conjugated with Alexa 594 (1:300; Invitrogen; A21207), while sections for NOS immunocytochemistry were incubated in donkey antigoat IgG conjugated with Alexa 594 (1:400; Invitrogen; A11058) in PBS at room temperature for $4 \mathrm{~h}$ or $4^{\circ} \mathrm{C}$ overnight. Following three $10 \mathrm{~min}$ rinses in PBS, sections were mounted in antifade solution, Vectashield hard setting mounting medium (Vector Laboratories; H1400), and observed and photographed using an Olympus BX60 fluorescent microscope and a Nikon D70 digital camera.

Statistical analysis. Input resistance was calculated from the slope of the current-voltage relationship using three points centered around zero current $( \pm 10 \mathrm{pA}$ for Type I interneurons and $\pm 160 \mathrm{pA}$ for Type II interneurons). All action potential parameters were measured from spontaneous spikes if the neuron was spontaneously active or from spikes evoked by a minimum suprathreshold current pulse delivered from rest if the neuron was not. AHP amplitude was measured as the difference between spike threshold and the minimum value of the membrane potential after the spike. The $I_{\mathrm{h}}$ ratio was calculated by dividing the amplitude of the voltage change in response to a $500 \mathrm{~ms}$ hyperpolarizing current pulse at the beginning of the pulse by the amplitude at the end of the pulse. Numerical values are reported as the mean \pm SEM. Statistical 




Figure 1. Distribution and expression of NPY/SOM/NOS ${ }^{+}$in striatal NPY interneurons in mice. $A$, Fluorescent photomicrographic montage of a coronal section of a BAC NPY-GFP ${ }^{+}$mouse brain illustrating the distribution and abundance of NPY interneurons in the neostriatum (Str). Note the sparse distribution of striatal NPY interneurons compared with cortical NPY interneurons. $\boldsymbol{B}_{1}-\boldsymbol{B}_{3}$, Higher-magnification photomicrographs illustrate GFP-NPY fluorescence in $\boldsymbol{B}_{1}$, NOS immunofluorescence in $\boldsymbol{B}_{2}$, and GFP and NOS merged in $\boldsymbol{B}_{\boldsymbol{3}}$. The small arrows indicate dimly fluorescent Type I somata, and the larger arrows indicate brighter Type II somata. Note that only Type I interneurons express NOS. $\boldsymbol{C}_{1}-\boldsymbol{C}_{3}$, GFP-NPY fluorescence in $\boldsymbol{C}_{1}$, SOM immunofluorescence in $\boldsymbol{C}_{2}$, and GFP and SOM merged in $\boldsymbol{C}_{3}$. Note that only Type I interneurons express SOM. $\boldsymbol{D}_{1}-\boldsymbol{D}_{3}$, GFP-NPY fluorescence in $\boldsymbol{D}_{1}, \mathrm{NPY}$ immunofluorescence in $\boldsymbol{D}_{2}$, and GFP and SOM merged in $\boldsymbol{D}_{3}$. Note that both typel and typell interneurons express NPY. $\boldsymbol{E}_{1}-\boldsymbol{E}_{3}$, NPY and NOS immunofluorescence in striatum from normal $\left[57 \mathrm{BL} / 6 \mathrm{~J}\right.$ mice shows exactly that same pattern of colocalization as in BACNPY-GFP ${ }^{+}$mice. $\boldsymbol{E}_{1}, \mathrm{NPY}$ immunofluorescence reveals two different types of NPY somata, a few very bright ones (presumed Type II NPY interneuron), marked by the white arrows, and more numerous less bright ones (presumed type I NPY interneuron), some marked by white double arrows. $E_{2}$, NOS immunofluorescence. Three NOS-immunoreactive neurons are marked by white double arrows. $\boldsymbol{E}_{3}, 0$ verlay of $\boldsymbol{E}_{1}$ and $\boldsymbol{E}_{2}$ shows that the bright NPY neurons do not colocalize NPY (white arrows), whereas the less

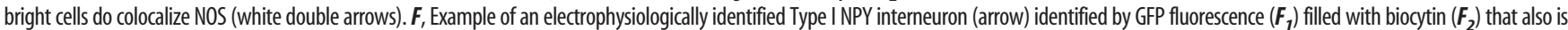
immunoreactive for $\mathrm{NOS}\left(\boldsymbol{F}_{3}\right)$, with the triple overlay shown in $\boldsymbol{F}_{4} \cdot \mathbf{G}$, Example of an electrophysiologically identified type IINPY interneuron (arrow) identified by GFP fluorescence $\left(\boldsymbol{G}_{7}\right)$ filled with biocytin $\left(\boldsymbol{G}_{2}\right)$ that is not immunoreactive for $\mathrm{NOS}\left(\boldsymbol{G}_{3}\right)$, with the triple overlay shown in $\boldsymbol{G}_{4}$. 
comparisons were made with ANOVA or Student's two-tailed $t$ test (Prism, version 4; GraphPad). Differences were considered to be significant if $p<0.05$.

\section{Results}

Striatal GFP-NPY interneurons under fluorescent illumination

Illumination at $485 \mathrm{~nm}$ revealed many fluorescent $\mathrm{GFP}^{+}$neurons throughout the cortex and, at lower density, in the neostriatum, as shown in Figure 1. At higher magnification, fluorescent striatal somata appeared to be composed of two distinct populations of medium-sized neurons. The majority of the somata exhibited moderately bright fluorescence and could be seen to emit from one to three straight, aspiny primary dendrites that could only be followed for a short distance. A second, smaller population of interneurons exhibited extremely bright fluorescence and issued five to nine primary aspiny dendrites. These dendrites exhibited significantly more branching than those of the former population and could be followed for distances up to 150 $\mu \mathrm{m}$. Henceforth, we will refer to the neurons of the former, larger population as Type I GFP-NPY interneurons and those of the latter as Type II GFP-NPY interneurons. Examples of fluorescent images of Type I and Type II GFP-NPY interneurons are shown in Figure $1 B-D$.

Using unbiased stereological cell counting (for methodological details, see Unal et al., 2011), we determined that there were $14,506 \pm 146$ GFP-NPY interneurons per striatal hemisphere ( $n=4$ hemispheres). Based on an estimated overall striatal cell population of 1.59 million in the mouse (Peterson et al., 1999; DíazHernández et al., 2005), GFP-NPY interneurons make up $\sim 0.9 \%$ of the total mouse striatal neuron population, compared with $\sim 0.52 \%$ of striatal neurons in rat (Oorschot, 1996; Larsson et al., 2001). Of mouse interneurons, 11,491 \pm 182.1 (79\%) were Type I GFP-NPY interneurons and $3016 \pm 146(21 \%)$ were Type II GFP-NPY ${ }^{+}$ interneurons.

\section{NPY immunoreactivity in striatal interneurons}

Because the expression of GFP in BAC transgenic mice is linked to transcriptional activity rather than to the level of expression of the mRNA or corresponding protein generated by the expression of the gene to which the GFP expression is linked (Gong et al., 2003), it was necessary to determine whether either or both types of striatal GFP-NPY interneurons expressed NPY. Qualitative light-microscopic analysis of striatal interneurons double labeled with a NPY antibody revealed that both Type I and Type II striatal interneurons express bright immunofluorescence for NPY, as shown in Figure 1. Of a total of 1196 Type I interneurons sampled in four hemispheres, 1040 or $87 \%$ were found to express NPY immunofluorescence. Similarly, of 362 Type II interneurons sampled, 340 or $94 \%$ expressed NPY immunofluorescence. The higher proportion of cells that exhibited immunofluores- cence for NPY among Type II interneurons was likely due to the greater intensity of NPY immunofluorescence in the Type II GF$\mathrm{P}-\mathrm{NPY}$ interneurons. Among both populations of GFP-NPY interneurons, the relatively small proportions of cells that did not express NPY immunofluorescence almost certainly reflects the greater sensitivity and ease of detection of the GFP marker compared with NPY immunofluorescence (Gong et al., 2003), rather than a true lack of expression of NPY in these interneurons. We will henceforth refer to GFP-NPY interneurons simply as NPY interneurons. Sample fluorescent micrographs of the colocalization of GFP-NPY fluorescence and NPY immunofluorescence are shown in Figure $1 D$.

\section{Colocalization of SOM and NOS immunofluorescence in striatal NPY interneurons}

To determine whether striatal NPY interneurons coexpress SOM and/or NOS, we reacted striatal slices from GFP-NPY mice for immunofluorescent visualization of SOM or NOS. An initial qualitative evaluation of this material suggested a clear distinction in that Type I NPY interneurons also expressed NOS or SOM, but Type II NPY interneurons did not. Subsequent quantitative analysis was made from every fourth $60 \mu \mathrm{m}$ coronal section from three striatal hemispheres, using standardized sampling grids $(554 \times 689 \mu \mathrm{m}$ for GFP-NPY and SOM or $840 \times$ 


\section{NPY-PLTS}

A

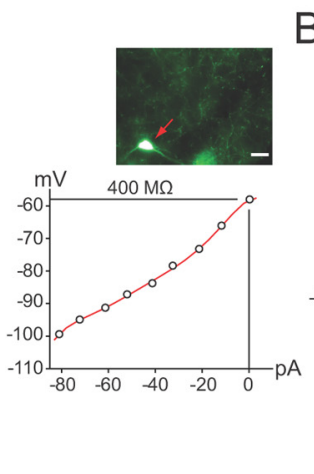

$\mathrm{C}_{1}$
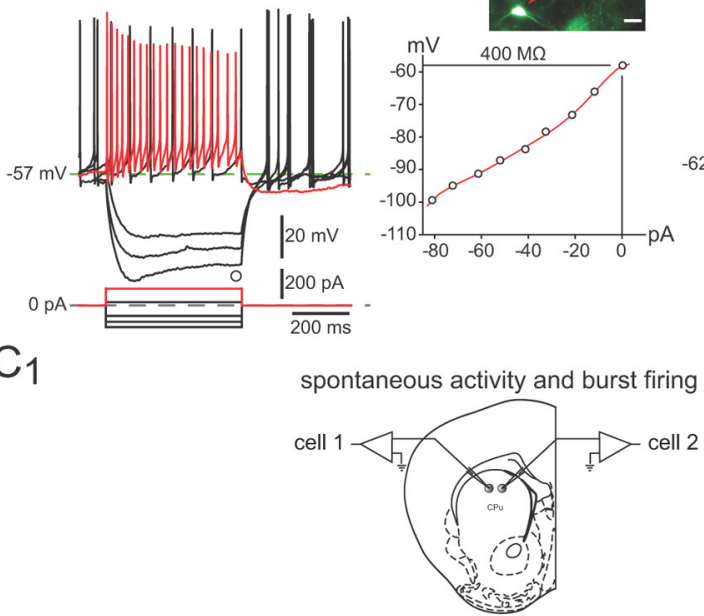

$\mathrm{C}_{2}$

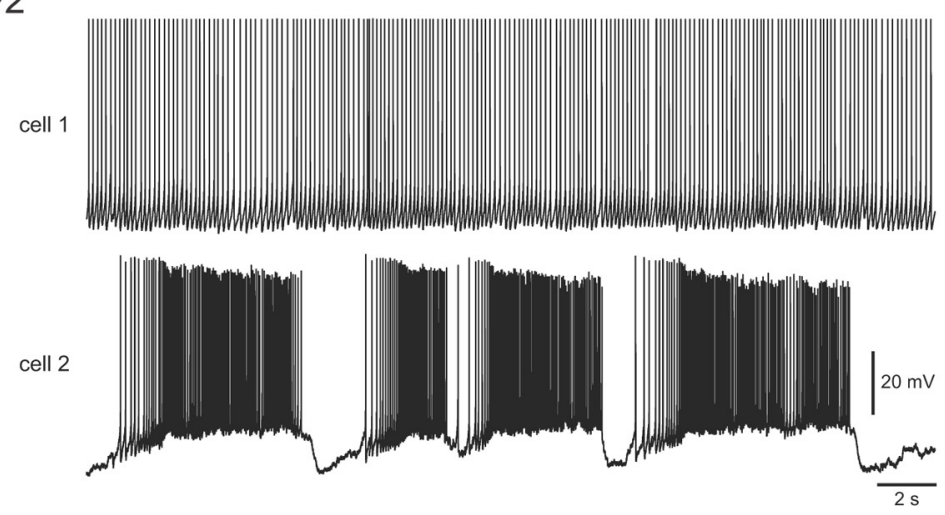

Figure 3. Intrinsic electrophysiological properties of NPY_PLTS interneurons. $\boldsymbol{A}$, Responses to negative and positive current pulses in an NPY-PLTS interneuron (inset) reveal high input resistance, a time-dependent $I_{\mathrm{h}}$-like sag in response to hyperpolarizing current injections, and a relatively depolarized resting membrane potential. Spike train elicited by depolarization (red trace) exhibits modest spike-frequency adaptation and marked accommodation. These interneurons exhibited spontaneous activity with little rebound after offset of hyperpolarizing current injections (black traces). B, Slightly more hyperpolarized NPY-PLTS interneuron exhibits a prolonged plateau potential (PLTS) following a depolarizing current injection (black trace) and rebound LTS and plateau following offset of hyperpolarizing current injections (red traces). $\boldsymbol{C}_{1}$, Approximate locations of the two cells shown in $\boldsymbol{C}_{2}$. $\boldsymbol{C}_{2}$, Two NPY_PLTS interneurons recorded simultaneously exhibit spontaneous activity. Top, Typical tonic firing pattern. Bottom, In a few cases, NPY-PLTS interneurons showed 8-10 mV membrane potential oscillations that separated prolonged epochs of higher frequency spontaneous burst firing activity.

$857 \mu \mathrm{m}$ for GFP-NPY and NOS) at a total of 370 sites (212 for GFP-NPY and SOM and 158 for GFP-NPY and NOS) with a $40 \times$ objective. For Type I NPY interneurons, 254 of 276 (92\%) were immunoreactive for SOM and 275 of 301 (91\%) were immunoreactive for NOS. In contrast, for Type II NPY interneurons, 6 of $72(8 \%)$ were immunoreactive for SOM and 5 of 111 $(4.5 \%)$ were immunoreactive for NOS. The small proportion of presumed Type I NPY interneurons that did not appear to colocalize SOM or NOS, and the similarly small proportion of presumed Type II NPY interneurons that did express SOM or NOS could have resulted from misclassification of NPY cell type based only on morphological appearance in GFP fluorescence, which is far less accurate than identification based on electrophysiological properties and/or morphology from biocytin fills, as well as from the intrinsic insensitivity of immunocytochemistry. In any event, the vast majority of Type I NPY interneurons colocal- ize both SOM and NOS, whereas a similarly large majority of Type II NPY interneurons do not. These two neurochemically distinct populations of striatal NPY interneurons are not the result of any artifactual genetic modification in the GFP-NPY mice as we repeated these studies in normal C57BL/6J mice and found the same two populations of NPY interneurons. Sample fluorescent micrographs of the colocalization of NPY GFP fluorescence or NPY immunofluorescence and SOM or NOS immunofluorescence in striata from GFP-NPY ${ }^{+}$transgenic mice and C57BL/6J mice are shown in Figure 1.

Four additional electrophysiologically identified GFP-NPY neurons (two Type I and two Type II) were processed for NOS immunofluorescence after recording and biocytin labeling. Both Type I NPY interneurons expressed SOM immunofluorescence, but neither Type II NPY interneurons expressed SOM immunofluorescence as shown in Figure 1, $F$ and $G$.

The morphological and neurochemical phenotypes of the Type I NPY interneurons were identical with those previously described for striatal GABAergic interneurons in the rat striatum that were electrophysiologically characterized as PLTS interneurons (Kawaguchi, 1993; Kawaguchi et al., 1995; Kubota and Kawaguchi, 2000). Type II NPY interneurons, however, have not been previously characterized electrophysiologically or neurochemically.

\section{Intrinsic electrophysiological properties of striatal interneurons}

Whole-cell current-clamp recordings from striatal slices from adult GFP-NPY mice revealed significant heterogeneity in a number of electrophysiological measures including the presence or absence of spontaneous activity, resting membrane, input resistance potential, action potential waveform, and responses to current injections, consistent with the existence of multiple electrophysiologically distinct subtypes of striatal interneurons.

For quantitative analysis, we first constructed a number of scatter plots in which the values for each of several measured variables were plotted against one another for each of the neurons, as shown in Figure 2. Relationships between two variables usually resulted in a clear separation or clustering of the neurons into two groups. A three-dimensional scatter plot and a current-firing frequency plot further supported our initial parcellation of striatal NPY interneurons into two distinct cell types based on neuroanatomical and neurochemical grounds. The parcellation of neurons on the basis of intrinsic electrophysiological properties mapped precisely onto the same two groups that were identified on the basis of GFP fluorescence brightness, dendritic morphology, and neurochemical phenotype (i.e., Type I and Type II NPY interneurons).

Neither Type I nor Type II NPY interneurons resembled electrophysiologically striatal SPN, FSI, cholinergic interneurons or 
striatal $\mathrm{TH}^{+}$interneurons (Kawaguchi, 1993; Kawaguchi et al., 1995; IbáñezSandoval et al., 2010; Tepper et al., 2010). However, Type I NPY interneurons displayed the electrophysiological characteristics of striatal PLTS interneurons described previously by Kawaguchi and others (Kawaguchi, 1993; Kawaguchi et al., 1995; Kubota and Kawaguchi, 2000; Centonze et al., 2002, 2003; Tepper et al., 2010). Conversely, striatal neurons exhibiting the electrophysiological characteristics of Type II NPY interneurons have not previously been described. The intrinsic electrophysiological properties of Type I and Type II NPY interneurons are detailed in the following sections.

\section{Type I NPY interneurons}

Type I NPY interneurons $(n=55)$ exhibited all the electrophysiological characteristics of striatal PLTS, NPY/SOM/NOS ${ }^{+}$ interneurons that have been described before in rats and mice (Kawaguchi, 1993; Kubota and Kawaguchi, 2000; Partridge et al., 2009; Gittis et al., 2010; Ibáñez-Sandoval et al., 2010). Because of this, we will henceforth refer to these as NPY-PLTS interneurons. Responses to current injection revealed a high input resistance, $744 \pm 51 \mathrm{M} \Omega$ (range, 310-1702 $\mathrm{M} \Omega$ ), and a marked time-dependent sag in response to hyperpolarizing current pulses $\left(I_{\mathrm{h}}\right)$ (Fig. $\left.3 A, B\right)$. NPY-PLTS interneurons also exhibited a prominent low-threshold spike (LTS) in response to depolarizing current injections from rest (Fig. 2 $C_{1}$ ) or as a rebound following the offset of hyperpolarizing current pulses (Fig. 3B). The most characteristic trait of NPY-PLTS interneurons was a prolonged plateau potential (Fig. $3 B$ ) following the termination of depolarizing or hyperpolarizing current injections (Kawaguchi, 1993; Kawaguchi et al., 1995; Partridge et al., 2009; Ibáñez-Sandoval et al., 2010; Tepper et al., 2010).

The mean resting membrane potential of NPY-PLTS interneurons was somewhat variable (range, -79 to $-51 \mathrm{mV}$ ) and relatively depolarized $(-63 \pm 1 \mathrm{mV})$ compared with SPNs and most other striatal interneurons. The majority of NPY-PLTS interneurons ( 30 of 44 neurons, $68 \%$; Fig. $3 C_{2}$ ) were spontaneously active, consistent with a previous report on GFP-NPY interneurons in slices from these mice (Partridge et al., 2009). Spontaneously active NPY-PLTS interneurons exhibited a mean firing rate of $6.4 \pm 0.5 \mathrm{~Hz}$ (range, $2-12 \mathrm{~Hz}$ ).

Some NPY-PLTS interneurons ( 6 of 30 neurons; $20 \%$ ) exhibited fluctuations in membrane potential of $8-10 \mathrm{mV}$ that were superficially similar to up and down states in SPNs in vivo (Wilson and Kawaguchi, 1996), except that the depolarized states were of longer duration and the hyperpolarized states of shorter duration than up and down states of SPNs. During the depolarized periods, NPY-PLTS interneurons fired in an accelerating bursty pattern (Fig. $3 C_{2}$, cell 2 ). Other spontaneously active striatal NPY-PLTS interneurons showed regular spiking activity (Fig. $3 C_{2}$, cell 1 ).

\section{Type II interneurons}

Type II NPY interneurons $(n=31)$ could be reliably targeted for whole-cell recording based on their distinct appearance under fluorescence imaging (see above). Whole-cell recordings revealed that these neurons exhibited a unique and distinct constellation

\section{NPY-NGF}

B

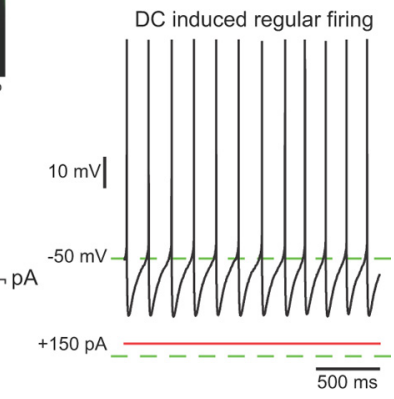

$\overline{200 \mathrm{~ms}}$

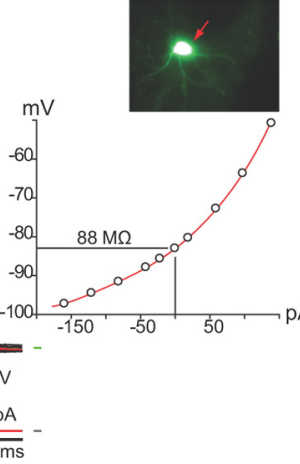

A, Whole-cell current-clamp recording of responses to negative and positive current pulses in an NPY-NGF interneuron reveal a marked inward rectification at depolarized potentials (inset). Note the very low input resistance and the very hyperpolarized resting membrane potential compared with NPY-PLTS interneurons. There is little spike frequency adaptation in the regular firing evoked by depolarizing current pulses. Note he large amplitude spike AHP. B, NPY-NGF interneurons did not exhibit spontaneous activity but depolarizing current injection

of electrophysiological characteristics not previously described for any other striatal neuron. Due to their electrophysiological and morphological homology with cortical and hippocampal GABAergic NPY-expressing interneurons in the hippocampus and cortex (Povysheva et al., 2007; Szabadics et al., 2007; Karagiannis et al., 2009; Karayannis et al., 2010) that will be described in succeeding sections, we will henceforth refer to Type II NPY interneurons as NPY-neurogliaform (NPY-NGF) interneurons.

Current injections revealed that these neurons exhibited a much lower input resistance than NPY-PLTS interneurons, $142 \pm 13 \mathrm{M} \Omega$ (range, 74-260 M $\Omega$ ), a fairly strong inward rectification to both hyperpolarizing and depolarizing current injections, and lacked the $I_{\mathrm{h}}$-mediated sag in response to hyperpolarizing current injection characteristic of NPY-PLTS interneurons (Fig. 4A). LTS and plateau potentials were never observed. The mean resting membrane potential was considerably more hyperpolarized than that of NPY-PLTS interneurons, $-88 \pm 1 \mathrm{mV}$ (range, -95 to $-79 \mathrm{mV}$ ), and as a consequence, all NPY-NGF interneurons were silent in the absence of stimulation.

NPY-NGF interneurons exhibited evoked action potentials of longer duration than SPNs or FSIs, $1.25 \pm 0.08 \mathrm{~ms}$ (range, 0.74 to $1.9 \mathrm{~ms} ; n=20$ ) at half-amplitude. NPY-NGF interneurons also exhibited a spike afterhyperpolarization that was notable for its large amplitude, $26 \pm 1 \mathrm{mV}(n=20)$.

The intrinsic electrophysiological properties of striatal NPY interneurons are summarized in Table 1.

\section{Synaptic connections of striatal NPY interneurons}

\section{Effects of cortical stimulation}

Previous reports showed that striatal NPY-immunoreactive interneurons receive excitatory cortical inputs (Vuillet et al., 1989; Partridge et al., 2009; Gittis et al., 2010), so we stimulated the cortex in the slice to determine whether NPY-PLTS and NPYNGF interneurons responded similarly. In practice, the recorded neurons were from 700 to $1400 \mu \mathrm{m}$ from the cortical stimulation site.

Cortical stimulation evoked monosynaptic EPSPs in both types of NPY interneurons (Fig. $5 A_{3}-A_{5}$ ). The mean values of all measured EPSP parameters (except onset latency) including amplitude (NPY-PLTS, $7.6 \pm 0.3 \mathrm{mV}, n=8$; vs NPY-NGF, $3.7 \pm$ 
Table 1. Intrinsic electrophysiological properties of striatal NPY interneurons

\begin{tabular}{|c|c|c|c|c|c|c|c|c|c|}
\hline Parameter & Input resistance (M $\Omega$ ) & $\operatorname{RMP}(\mathrm{mV})$ & AP threshold (mV) & AP width $50 \%$ (ms) & AP amplitude (mV) & AHP amplitude (mV) & AHP duration (ms) & Spontaneous firing rate (Hz) LTS & $I_{\mathrm{h}}$ ratio \\
\hline & $744 \pm$ & $-63 \pm$ & $-45 \pm 1(-53$ to -38$)$ & $1.3 \pm 0.05(0.75-2)$ & $74 \pm 1.8(56-108)$ & $(9-25)$ & $134 \pm 11$ & $6.4+0.5(2-12) 30 / 44$ & $1.1 \pm 0$ \\
\hline NPY-NGF (19) & $142 \pm 13^{*}(74-260)$ & $-88 \pm 1^{*}(-95$ to -79$)$ & $-44 \pm 1(-48$ to -39$)$ & $1.25 \pm 0.08(0.74-1.9)$ & $80 \pm 2(64-101)$ & $26 \pm 1^{*}(20-32)$ & $140 \pm 5$ & $0 / 19$ & $91 \pm 0$ \\
\hline
\end{tabular}

All values are means \pm SEM. The numbers in parentheses refer to the range of values. $n$ refers to number of neurons from which the measurements were obtained. AP, Action potential; RMP, resting membrane potential; AHP, afterhyperpolarizing; LTS, low threshold spike.

${ }^{*} p<0.001 ; \# p 0.05$, Student's two-tailed $t$ test.

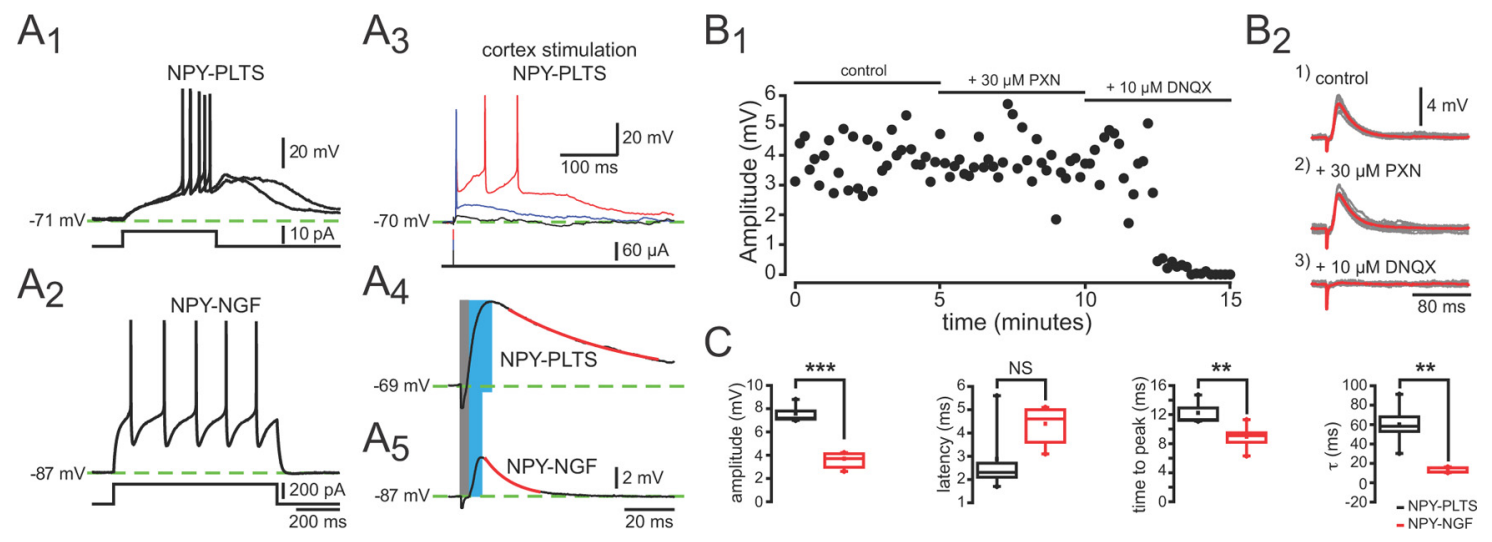

Figure 5. Response of striatal NPY interneurons to cortical stimulation. $\boldsymbol{A}$, Responses to depolarizing current injection for two striatal NPY ${ }^{+}$neurons types. Depolarization elicits a slow depolarization, LTS, and plateau potential in the NPY_PLTS interneuron $\left(\boldsymbol{A}_{7}\right)$ but only regular spiking in the NPY-NGF interneuron $\left(\boldsymbol{A}_{2}\right)$. $\boldsymbol{A}_{3}-\boldsymbol{A}_{5}$, Corticostriatal stimulation evoked an EPSP in both NPY interneuron types. Note that the EPSP in NPY-PLTS interneurons is large and in response to suprathreshold stimuli produces a long-lasting plateau potential $\left(\boldsymbol{A}_{3}, \boldsymbol{A}_{4}\right)$. In contrast, EPSPs are smaller in NPY-NGF interneurons (note difference in scale bars) and usually does not elicit spikes $\left(\boldsymbol{A}_{5}\right)$. The gray and blue bars show where we measured the values for the onset latency and time to peak. The red line is the fit of a first-order exponential to determine the time constant. $\boldsymbol{B}_{1}$, Time course of drug effects on the EPSP. $\boldsymbol{B}_{2}$, Cortical stimulation evoked a short latency monosynaptic DPSP in an NPY-NGF interneurons (1). The DPSP is not affected by PXN (2). The AMPA/kainate channel blocker DNQX (10 $\mu$ m) completely eliminates the DPSP, showing that it is a glutamatergic EPSP (3). C, Summary plots for EPSP parameters from striatal NPY-PLTS and NPY-NGF interneurons. ${ }^{* *} p<0.01,{ }^{* * *} p<0.001$.

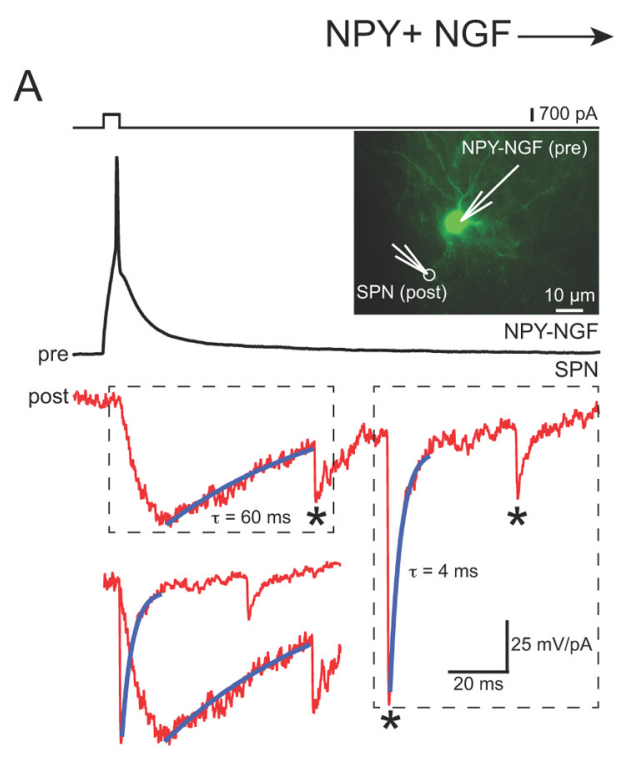
SPN

$B$
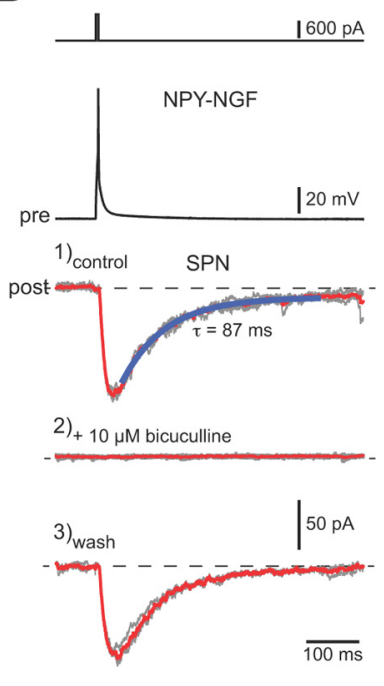

Figure 6. Paired recordings between NPY-NGF interneurons and SPNs. $\boldsymbol{A}$, The top traces show intracellular current pulse and a single spike response in a presynaptic (pre) NPY-NGF interneuron shown in the inset to the right. The middle trace shows a slow IPSC in response

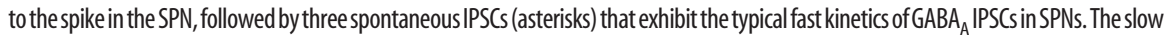
IPSC has a long rise time as well as an extremely long $\tau_{\text {decay }}$. The bottom trace is an overlay of the two boxed areas in the middle trace for comparison of the rise and decay times of the fast and slow IPSCS. $\boldsymbol{B}$, The top traces show a different presynaptic NPY-NGF (pre) evoked to fire a single spike by a brief intracellular current pulse. Bottom traces: 1, Control slow IPSC in a postsynaptic NPY-NGF interneuron; 2, slow

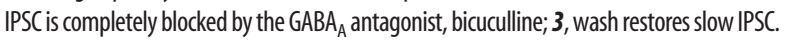

$0.2 \mathrm{mV}, n=5 ; p<0.001$ ), rise time (NPY-PLTS, $12.2 \pm 0.7 \mathrm{~ms}$, $n=8$; vs NPY-NGF, $9.3 \pm 0.4 \mathrm{~ms}, n=5 ; p<0.003)$, and $\tau_{\text {decay }}$ (NPY-PLTS, $60.2 \pm 10 \mathrm{~ms}, n=8$; vs NPY-NGF, $11.9 \pm 1 \mathrm{~ms}$, $n=5 ; p<0.002$ ) were significantly greater for NPY-PLTS cells than NPY-NGF cells, presumably reflecting, at least in part, the much higher input resistance of the NPY-PLTS cells. Cortical stimulation of NPY-PLTS interneurons often elicited a large plateau depolarization lasting hundreds of milliseconds that gave rise to spiking as previously described by Kawaguchi (1993), an example of which is shown in Figure $5 A_{3}$. In contrast, such prolonged depolarizations were never seen in NPY-NGF interneurons nor was spiking observed in response to cortical stimulation (Fig. $5 A_{5}$ ). The unusually small size of the maximal cortically evoked EPSP in the NPY-NGF interneurons, and its inability to elicit spiking in our preparation, might indicate the existence of an important extracortical excitatory input to the NPY-NGF interneurons. Consistent with this idea, English et al. (2011) have just described the existence of a nicotinic cholinergic input to the NPY-NGF interneurons capable of eliciting action potentials.

Cortically evoked depolarizing potentials were unaffected by picrotoxin (PXN) $(30 \mu \mathrm{M})$, indicating the lack of direct activation of intrastriatal inhibitory circuits by the cortical stimulus. However, addition of the AMPA/kainate glutamate receptor antagonist, 6,7-dinitroquinoxaline-2,3-dione (DNQX) (10 $\mu \mathrm{M})$, completely blocked the EPSPs as illustrated in a repre- 




Figure 7. Photomicrographs of electrophysiologically identified NPY-PLTS and NPY-NGF interneurons stained with biocytin after whole-cell recording. $A$, NPY-NGF interneuron. Note the dense and highly branched and compact dendritic and axonal arborizations. The inset shows part of the highly varicose, dense local collateral arborization at high magnification. $\boldsymbol{B}$, NPY-PLTS interneuron. The arrowhead points to axon initial segment, and arrows point to parts of the axon. Note the sparse and poorly branched dendritic and axonal arborizations. The top inset shows a varicose segment of a secondary dendrite at high magnification. The bottom inset shows part of the diffuse axonal arborization with less prominent, more widely and irregularly spaced varicosities than in the NPY-NGF cell in A. C, A second NPY-NGF interneuron displaying a rich, branched dendritic tree. D, A second NPY-PLTS interneuron exhibiting the typical sparse and extended dendritic arborization. The arrows point to parts of the sparse axonal arborization. The inset shows sparse spine-like dendritic specializations. The scale bar in $\boldsymbol{B}$ applies to $\boldsymbol{A}$ and $\boldsymbol{B}$. The scale bar in $\boldsymbol{D}$ applies to $\boldsymbol{C}$ and $\boldsymbol{D}$.

sentative NPY-NGF interneuron in Figure $5, B_{1}$ and $B_{2}$. The same sensitivity of the cortical EPSPs to DNQX blockade was observed in NPY-PLTS interneurons (data not shown).

\section{Synaptic responses of SPNs to NPY interneurons in} paired recordings

To determine the characteristics of the synaptic transmission between NPY-PLTS or NPY-NGF NPY interneurons and SPNs, we patched onto NPY interneurons and then with one or two additional micropipettes patched onto SPNs and recorded them in voltage clamp at $-70 \mathrm{mV}$. The responses of SPNs to evoked spikes in NPY interneurons were markedly different in pairs consisting of presynaptic NPY-PLTS interneurons compared with those consisting of presynaptic NPY-NGF.

With five NPY-PLTS interneurons as presynaptic neurons, recordings were made from nine SPNs, four with normal internal in the SPN and five with a $\mathrm{CsMeSO}_{4}$ internal. We were unable to detect any postsynaptic response at any membrane potential in these nine pairs. An additional 11 NPY-PLTS neurons were recorded with Alexa 594 in the recording pipette to visualize their axonal arborization, to enable recording from SPNs within the axonal arborization of the presynaptic NPY-PLTS interneuron. With these 11 Alexafilled NPY-PLTS interneurons, a total of 21 SPNs were recorded with the $\mathrm{CsCl}$ internal solution. Three of these SPNs were found to be postsynaptic to a NPY-PLTS interneuron (one of two from one NPY-PLTS interneuron and two of three from another). The mean IPSC amplitude was $22.3 \pm 9.4 \mathrm{pA}$ (range, $11-41 \mathrm{pA}$ ). The IPSC rise time was $1.0 \pm 0.1 \mathrm{~ms}$ (range, $0.8-1.3 \mathrm{~ms}$ ) and the $\tau_{\text {decay }}$ was $10.3+$ $1.2 \mathrm{~ms}$ (range, $8-12 \mathrm{~ms}$ ). The low frequency of the connectivity between NPY-PLTS and randomly chosen SPNs is consistent with previous reports (Gittis et al., 2010).

However, in 29 pairs consisting of a presynaptic NPY-neurogliaform interneuron $(n=22)$ and a SPN, 25 of the postsynaptic SPNs responded with a monosynaptic IPSC as shown in Figure 6. SPNs in these pairs were recorded with an internal solution containing $134 \mathrm{~mm}(n=13)$ or $140 \mathrm{~mm}(n=16) \mathrm{CsCl}$. The mean latency from the peak of the presynaptic spike to the onset of the IPSC was $2.3 \pm 0.15 \mathrm{~ms}$. The connection probability was $>86 \%$ for these pairs of neurons that were within $100 \mu \mathrm{m}$ of each other, which is as great or greater than that between FSIs and SPNs that exhibit the highest probability of synaptic connections of any cell 
A

\section{NPY-PLTS}
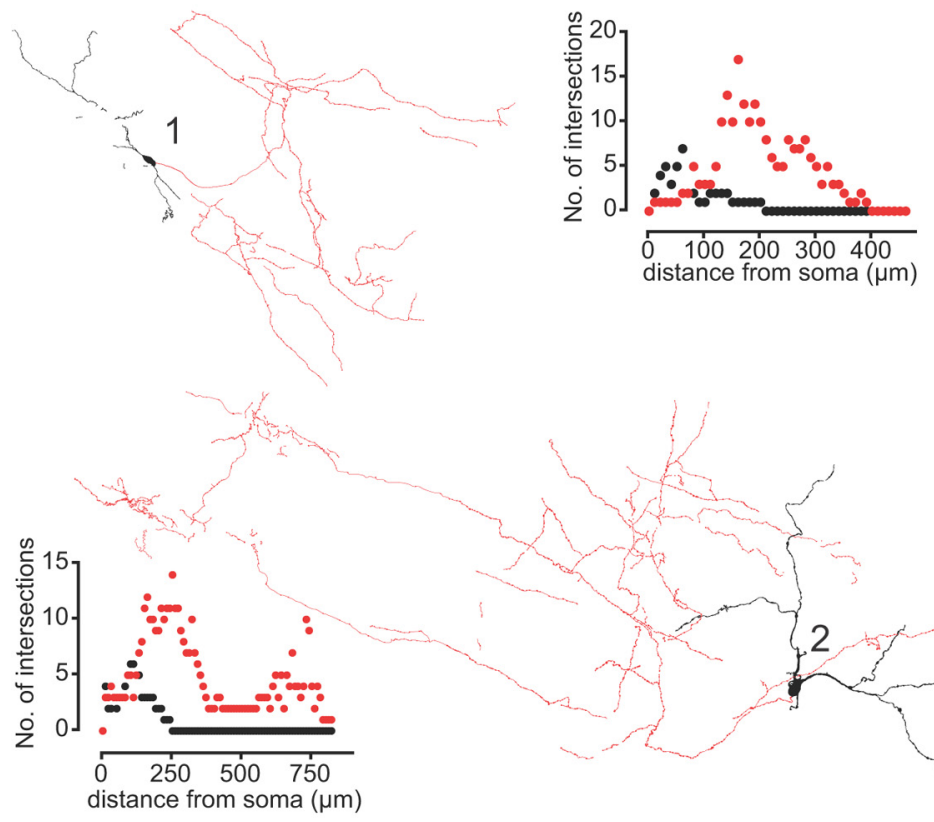

$\mathrm{B}$

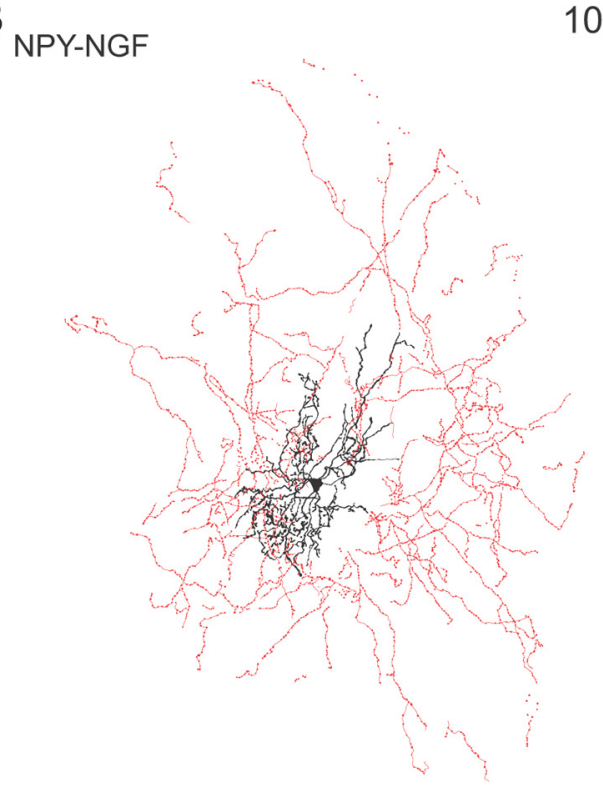

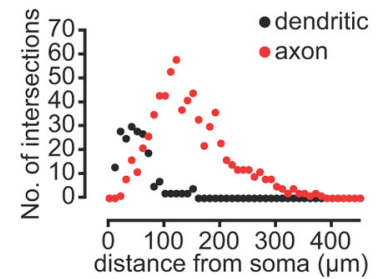

Figure 8. Drawing tube reconstructions of typical examples of NPY-PLTS and NPY-NGF interneurons filled with biocytin during whole-cell recording. $\boldsymbol{A}$, Two representative NPY-PLTS interneurons. Note the simple and minimally branched aspiny dendritic tree and the poor and diffuse axonal arborization that extends far from the cell of origin and its dendritic tree. The axons exhibit long linear unbranched segments lacking the small varicosities present in the more highly branched parts of the arborization. $\boldsymbol{B}$, NPY-NGF interneuron showing a very compact and highly branched aspiny dendritic tree. The axonal arborization is centered around and extends beyond the soma and dendritic tree, and is highly branched and heavily invested with prominent varicosities, presumably synaptic boutons. The insets show some of the Sholl plots from which the data in Table 2 were derived.

from FSIs or SPNs in exhibiting an unusually slow rise time, $10 \pm 1 \mathrm{~ms}$ (range, 3-19 $\mathrm{ms})$, and a very slow decay with $\tau_{\text {decay }}=$ $123 \pm 42 \mathrm{~ms}$ (range, 29-1125; $n=25$; compare Fig. 6). One cell with a $\tau_{\text {decay }}=$ $1125 \mathrm{~ms}$ was an outlier, but even with this cell removed, the mean $\tau_{\text {decay }}$ was $83 \pm 6$ ms (29-127 ms; $n=24)$. Neither the slow onset nor the long decay were artifacts of poor voltage clamp since we routinely observed much faster rise times ( $\leq 1 \mathrm{~ms}$ ) in the same SPNs for spontaneous IPSCs that presumably arise in large part, from FSIs (Koós and Tepper, 2002), or IPSCs that arise from NPY-PLTS interneurons in other paired recordings (data not shown).

\section{Morphology of biocytin-labeled striatal $\mathrm{NPY}^{+}$interneurons}

Sixteen biocytin-filled NPY interneurons (11 NPY-PLTS and 5 NPY-NGF) were recovered in suitable condition for quantitative morphological analysis. Photomicrographs of four representative filled neurons are shown in Figure 7. NPYPLTS somata were most often ovoid (8 of 11; 73\%), while NPY-NGF somata were most frequently round ( 4 of 5; 80\%). The remaining somata of both types were pyramidal shaped.

NPY-PLTS somata $(15.6 \pm 0.8 \times$ $9.5 \pm 0.5 \mu \mathrm{m})$ were slightly larger than NPY-NGF somata $(12.6 \pm 0.7 \times 9.4 \pm$ $0.6 \mu \mathrm{m})$. The mean number of primary dendrites from NPY-PLTS interneurons was significantly smaller than for NPYNGF interneurons $(2.7 \pm 0.2$ compared with $6.8 \pm 0.6 ; n=5 ; p<0.05)$. The values for the NPY-PLTS interneurons are in agreement with that reported by others for the PLTS-SOM/NOS/NPY ${ }^{+}$interneuron in rats and mice (Kawaguchi, 1993; Kawaguchi et al., 1995; Kubota and Kawaguchi, 2000; Partridge et al., 2009).

The dendritic arborization of NPYPLTS interneurons was relatively sparse and poorly branched, as previously described by Kawaguchi (1993) for rat SOM/NOS PLTS interneurons and Partridge et al. (2009) for striatal NPY interneurons in the mouse. NPY-PLTS interneurons issued two to four primary dendrites that branched between 40 and $60 \mu \mathrm{m}$ from the soma and gave a rise to sparse, poorly branched arborization of

pair types in striatum found thus far (Gittis et al., 2010; Planert et al., 2010; Tepper et al., 2010). The mean amplitude of the IPSC was $70 \pm 14 \mathrm{pA}$ (range, 3-223 pA), smaller than that of FS $\rightarrow$ SPN IPSC but greater than that of SPN $\rightarrow$ SPN IPSCs obtained under similar recording conditions (Koós and Tepper, 1999; Tunstall et al., 2002; Koós et al., 2004; Tecuapetla et al., 2009).

Most significantly, the NPY-NGF $\rightarrow$ SPN IPSCs also differed very significantly from previously reported IPSCs originating secondary and tertiary dendrites that extended for up to $800 \mu \mathrm{m}$, with peak Sholl intersections between 100 and $200 \mu \mathrm{m}$ from the soma. In striking contrast, NPY-NGF interneurons issued five to nine primary dendrites that branched between 20 and $30 \mu \mathrm{m}$ from the soma and gave rise a much denser and more compact arborization of short secondary, tertiary, and quaternary dendrites whose Sholl intersections peaked near $75 \mu \mathrm{m}$ from the soma. These 


\begin{tabular}{|c|c|c|c|c|c|c|c|c|c|c|c|}
\hline & \multirow[b]{3}{*}{$\operatorname{Area}\left(\mu \mathrm{m}^{2}\right)$} & \multirow[b]{3}{*}{ Perimeter $(\mu \mathrm{m})$} & \multirow{2}{*}{\multicolumn{2}{|c|}{ Soma size $(\mu \mathrm{m})$}} & \multirow[b]{3}{*}{ Primary dendrites } & \multirow{2}{*}{\multicolumn{3}{|c|}{ Processes on dendrites }} & \multicolumn{3}{|l|}{ Sholl analysis } \\
\hline & & & & & & & & & \multirow[b]{2}{*}{ No. of dendritic tips } & \multirow{2}{*}{$\begin{array}{l}\text { Mean dendritic field } \\
\text { diameter }(\mu \mathrm{m})\end{array}$} & \multirow{2}{*}{$\begin{array}{l}\text { Mean axonal field } \\
\text { diameter }(\mu \mathrm{m})\end{array}$} \\
\hline & & & Width & Height & & Varicose & Spine & Both & & & \\
\hline NPY-PLTS (11) & $107 \pm 13(81-215)$ & $48 \pm 3(36-68)$ & $15.6 \pm 0.8(12-20)$ & $9.5 \pm 0.5(7-13)$ & $2.7 \pm 0.2(2-4)$ & $11 / 11$ & $11 / 11$ & $11 / 11$ & $\begin{array}{l}7.7 \pm 0.6(5-13) \\
n=8\end{array}$ & $\begin{array}{l}573 \pm 91(260-870) \\
n=8\end{array}$ & $\begin{array}{l}723 \pm 169(400-970) \\
n=5\end{array}$ \\
\hline NPY-NGF (5) & $106 \pm 11(81-131)$ & $51 \pm 5(41-70)$ & $12.6 \pm 0.7^{\#}(11-15)$ & $9.4 \pm 0.6(8-11)$ & $6.8 \pm 0.6^{*}(5-9)$ & $5 / 5$ & $4 / 5$ & $4 / 5$ & $\begin{array}{l}51.4 \pm 6.1^{*}(38-68) \\
n=4\end{array}$ & $\begin{array}{l}222 \pm 22^{\#}(150-280) \\
n=4\end{array}$ & $\begin{array}{l}650 \pm 150(500-800) \\
n=2\end{array}$ \\
\hline
\end{tabular}

All values are means \pm SEM. The numbers in parentheses refer to the range of values. $n$ refers to number of neurons from which the measurements were obtained.

${ }^{*} p<0.001 ;{ }^{\#} p<0.05$, Student's two-tailed $t$ test.

Scholl results are very similar to those reported for cortical NPYNGF interneurons (Povysheva et al., 2007), as illustrated in Figure 8.

The dendrites of both types of NPY interneurons exhibited varicosities and sparsely distributed spines, in agreement with data reported by Partridge et al. (2009) for striatal NPY interneurons in the same transgenic mouse line.

The axonal arborizations of NPY-PLTS and NPY-NGF interneurons were also distinctly different as illustrated in the reconstructions in Figure 8. The initial region of the axon from NPY-PLTS interneurons extended linearly away from the soma, sometimes for several hundred micrometers, and branched only occasionally, forming a very sparse, extended axonal field, most of which was distant from and non-overlapping with the dendritic tree, as shown for two example NPY-PLTS interneurons in Figures $7, B$ and $D$, and $8, A_{1}$ and $A_{2}$. The initial axonal region and the long, straight axonal trajectories were mostly smooth, in contrast to the widely spaced, more highly branched regions in which small axonal varicosities were visible.

In marked contrast, the axonal arborization of NPY-NGF interneurons consisted of a dense plexus of highly branched thin processes, heavily beaded with prominent en passant varicosities, presumably indicative of synaptic boutons. The axon ramified radially and was densest from 100 to $200 \mu \mathrm{m}$ from the soma (Figs. 7A, $8 B$, Sholl plot). The long, straight, and nonvaricose axonal branches typical of some segments of NPY-PLTS axons were not seen. None of the NPY-PLTS or NPY-NGF cells evidenced a single long axon that projected away from the immediate locale of the parent cell. Sholl analysis data from biocytin-labeled striatal NPY interneurons are shown in Table 2.

\section{Discussion}

\section{Striatal NPY-expressing interneurons comprise two distinct populations}

Striatal NPY interneurons in the mouse comprise two distinct populations of GABAergic NPY-expressing interneurons, clearly distinguishable based on intrinsic electrophysiological characteristics, synaptic responses, and morphological and neurochemical properties each of which defines the same two populations. NPYPLTS interneurons, the more abundant of the two, make up more than three-quarters of the $\mathrm{NPY}^{+}$striatal neuron population, with the less abundant NPY-NGF cells comprising $\sim 21 \%$ of the total. NPY-NGF interneurons expressed brighter GFP fluorescence and NPY immunofluorescence, suggesting that these neurons express higher levels of NPY transcriptional activity than NPY-PLTS interneurons (Gong et al., 2003).

Most NPY-PLTS interneurons were immunoreactive for SOM and NOS, whereas most NPY-NGF interneurons were not, and would therefore have been missed in previous studies of striatal interneurons relying on SOM, NOS, or NADPH diaphorase immunocytochemistry. The present results and previous studies (Kubota and Kawaguchi, 2000; Gittis et al., 2010) demon- strate that the classical neurotransmitter for both NPY-PLTS and NPY-NGF interneurons is GABA.

Previous studies in rat have reported a significant lack of colocalization of NPY, SOM, and/or NOS in up to 33\% of striatal interneurons expressing any of these markers (Rushlow et al., 1995; Figueredo-Cardenas et al., 1996; Rymar et al., 2004), reporting expression of SOM and/or NOS without NPY, but with all NPY-immunopositive neurons colocalizing SOM. However, our results indicate that $\sim 20 \%$ of NPY-expressing interneurons fail to express SOM or NOS at levels detectable by immunofluorescence. This could reflect a species difference, similar to differences in colocalization of neuropeptides in cortical GABAergic interneurons (Xu et al., 2010) or in the proportions of striatal neurons consisting of NPY-expressing interneurons in the present study and of different striatal interneurons reported previously (Wu and Parent, 2000). However, it is also possible that identification on the basis of a GFP reporter allowed detection of some NPY-expressing neurons that would have been below the limits of detection with immunoreactivity alone (Gong et al., 2003; Chandler et al., 2007), as was recently shown for striatal TH interneurons (Ibáñez-Sandoval et al., 2010).

\section{Intrinsic electrophysiological properties of NPY-PLTS and NPY-NGF interneurons}

NPY-PLTS interneurons exhibited characteristics identical with the PLTS interneurons described by Kawaguchi (1993) in rat striatum. In both rat and mouse, these GABAergic interneurons also colocalized both SOM and NOS and were characterized by a high input resistance, LTS, and prolonged plateau potentials in response to depolarizing current pulses. Approximately twothirds of the NPY-PLTS neurons in our sample were spontaneously active. Thus, there is at least one cell type in striatum other than cholinergic interneurons that is tonically active.

The electrophysiological properties of NPY-NGF interneurons were strikingly different and have not previously been described for any striatal neuron (but see below). NPY-NGF interneurons exhibited some characteristics similar to those of SPNs, including a hyperpolarized membrane potential, relatively low input resistance, marked inward rectification, relatively long duration action potentials, absence of spontaneous activity, and regular firing in response to depolarizing current injections (Kawaguchi et al., 1989; Wilson, 1993). These similarities may have resulted in these neurons being mistaken for SPNs when previously encountered by others, rather than as a distinct cell type. This could account for the fact that they have not previously been reported even though there are in the neighborhood of 3000 or more such neurons per striatum. However, the mean input resistance of NPY-NGF interneurons is two to three times greater than that of SPNs in the same slices. Most telling, however, was the presence of a distinctive deep AHP following spikes not seen 
in SPNs, which provided an unambiguous electrophysiological discriminator between NPY-NGF interneurons and SPNs.

\section{Excitatory synaptic responses of striatal NPY interneurons}

NPY-PLTS and NPY-NGF interneurons responded to cortical stimulation with monosynaptic EPSPs. The onset latencies of the cortically evoked EPSPs did not differ between NPY-PLTS and NPY-NGF interneurons, but all other measured parameters did. Cortically evoked EPSPs in NPY-PLTS interneurons exhibited significantly greater amplitudes, longer time to peak, and a greater $t_{\text {decay }}$ than EPSPs in NPY-NGF interneurons. These differences are consistent with the significantly greater input resistance of NPY-PLTS interneurons compared with NPY-NGF interneurons.

\section{Synaptic connectivity of NPY-PLTS and NPY-NGF NPY interneurons to SPNs}

In nine pairs of simultaneously recorded NPY-PLTS interneurons and nearby SPNs, we failed to find any synaptic connections, consistent with the difficulty of finding such connections previously (Gittis et al., 2010). But when the presynaptic NPY-PLTS was filled with Alexa 594 during recording allowing visualization of the presynaptic axonal arborization, and potential postsynaptic SPNs were selected within this area, the probability of connection rose to $>14 \%$. This implies that the sparseness and extended nature of the NPY-PLTS interneuronal axonal arborization accounts in large part for the difficulty in obtaining synaptically connected pairs in the present study and previously (Gittis et al., 2010). The extended nature of the axonal arborization also suggests that NPY-PLTS interneurons might play a role in integrating activity over relatively remote, but functionally related, striatal regions.

In addition, it is possible that some NPY-PLTS interneurons rely on neuromodulatory actions of SOM (Vilchis et al., 2002; Galarraga et al., 2007; Lopez-Huerta et al., 2008) rather than on GABAergic inhibition for their synaptic effects. It is also possible that the NPY-PLTS interneurons primarily affect dendritic excitability that is difficult to see with somatic recordings and/or that these connections are strengthened under other experimental conditions (Dehorter et al., 2009; Gittis et al., 2010).

The NPY-NGF $\rightarrow$ SPN synapses, however, had an extremely high probability of synaptic connection to nearby SPNs, greater than that of any other previously reported striatal neuron type including the FSI (Tepper et al., 2010) and failures were not observed. These observations are consistent with the dense, highly branched axonal arborization of the NPY-NGF interneuron that is laden with varicosities (presumably synaptic boutons). The size of the synaptic currents and the exceedingly reliable nature of the synapse indicate that the NPY-NGF GABAergic interneurons provide a previously unappreciated source of powerful inhibition to SPNs and thus play an important role as mediators of powerful feedforward inhibition to SPNs. This is in sharp contrast to NPYPLTS interneurons, whose anatomical and electrophysiological characteristics suggest a different role in striatal microcircuitry.

\section{Similarity of NPY-NGF interneurons to neocortical and hippocampal NPY GABAergic interneurons}

The most striking and unique feature of NPY-NGF interneurons is the slow $\mathrm{GABA}_{\mathrm{A}}$-mediated IPSC they evoke in SPNs that exhibits a severalfold longer rise time and slower decay than the IPSCs originating from NPY-PLTS, FS (Koós and Tepper, 2002; Koós et al., 2004), or TH interneurons (Ibáñez-Sandoval et al., 2010). The slow decay of the NPY-NGF interneuron IPSC is unlikely to reflect electrotonic filtering, since distally located $\mathrm{SPN} \rightarrow$ SPN synapses result in IPSCs with a significantly faster time course (Koós et al., 2004; Tecuapetla et al., 2009).

Similar slow $\mathrm{GABA}_{\mathrm{A}}$ receptor-mediated IPSCs have been previously described in the hippocampus and neocortex (Pearce, 1993; Szabadics et al., 2007). Although initially ascribed to action at $\mathrm{GABA}_{\mathrm{B}}$ receptors (Tamás et al., 2003), more recent data demonstrate conclusively the existence of a slow $\mathrm{GABA}_{\mathrm{A}}$ receptormediated IPSC that originates from specialized cortical and hippocampal interneurons including neurogliaform cells (Price et al., 2005) and Ivy cells (Fuentealba et al., 2008), both of which represent subtypes of NPY-expressing interneurons (Karagiannis et al., 2009; Tricoire et al., 2010).

Striatal NPY-NGF interneurons not only share the coexpression of NPY but also similar intrinsic electrophysiological and neuroanatomical properties with these cortical interneurons (Povysheva et al., 2007). These similarities are as striking as the previously noted correspondence between the properties of $\mathrm{PV}^{+}$ FS interneurons in cortical areas and the neostriatum (Kawaguchi and Kubota, 1993; Koós and Tepper, 1999; Tepper et al., 2010). These observations lend further support to the notion that the functional diversity of GABAergic interneurons reflects, at least in part, mechanisms of cell type specification that are in play before or independently of the integration of these neurons into recipient circuits.

\section{Functional significance}

The subdivision of striatal NPY-expressing interneurons into two populations differing with respect to intrinsic electrophysiological properties, synaptic responses, neurochemical phenotype, and morphology indicates that the differences between NPYPLTS and NPY-NGF striatal NPY interneurons are much greater than their similarity, which is restricted solely to the expression of NPY. By analogy to neocortical and hippocampal neurogliaform neurons whose IPSC kinetics was shown to result from the unique properties of the synaptic GABA transient and receptor desensitization (Szabadics et al., 2007; Karayannis et al., 2010), it is possible that striatal NPY-NGF interneuron synapses are similarly specialized. These data strongly suggest that the two subtypes of striatal NPY interneurons play very distinct roles in intrastriatal circuitry and therefore ought to be considered as two functionally distinct interneurons, as different from one another as FS and PLTS interneurons are. This suggestion is strongly supported by the recent description of the critical role played by the NPY-NGF interneurons in a feedforward inhibition of spiny neurons mediated through the cholinergic interneuron (English et al., 2011).

These present results are consistent with and extend recent findings (Ibáñez-Sandoval et al., 2010; Tepper et al., 2010), which suggest that striatal GABAergic interneurons are more diverse than previously appreciated in terms of the number of electrophysiologically, morphologically, neurochemically, and functionally distinct subtypes. In this respect, striatal GABAergic interneurons can now be seen to express a similar diversity of electrophysiological, neurochemical, and anatomical properties as their better characterized counterparts in the cortex and hippocampus (Freund and Buzsáki, 1996; Klausberger and Somogyi, 2008; Xu et al., 2010).

\section{References}

Calabresi P, Centonze D, Gubellini P, Pisani A, Bernardi G (2000) Acetylcholine-mediated modulation of striatal function. Trends Neurosci 23:120-126. 
Centonze D, Bracci E, Pisani A, Gubellini P, Bernardi G, Calabresi P (2002) Activation of dopamine D1-like receptors excites LTS interneurons of the striatum. Eur J Neurosci 15:2049-2052.

Centonze D, Grande C, Usiello A, Gubellini P, Erbs E, Martin AB, Pisani A, Tognazzi N, Bernardi G, Moratalla R, Borrelli E, Calabresi P (2003) Receptor subtypes involved in the presynaptic and postsynaptic actions of dopamine on striatal interneurons. J Neurosci 23:6245-6254.

Chandler KJ, Chandler RL, Broeckelmann EM, Hou Y, Southard-Smith EM, Mortlock DP (2007) Relevance of BAC transgene copy number in mice: transgene copy number variation across multiple transgenic lines and correlations with transgene integrity and expression. Mamm Genome 18:693-708.

Dehorter N, Guigoni C, Lopez C, Hirsch J, Eusebio A, Ben-Ari Y, Hammond C (2009) Dopamine-deprived striatal GABAergic interneurons burst and generate repetitive gigantic IPSCs in medium spiny neurons. J Neurosci 29:7776-7787.

Díaz-Hernández M, Torres-Peraza J, Salvatori-Abarca A, Morán MA, Gómez-Ramos P, Alberch J, Lucas JJ (2005) Full motor recovery despite striatal neuron loss and formation of irreversible amyloid-like inclusions in a conditional mouse model of Huntington's disease. J Neurosci 25:9773-9781.

English DF, Ibáñez-Sandoval O, Stark E, Tecuapletla F, Buzsáki G, Deisseroth K, Tepper JM, Koós T (2011) Novel GABAergic circuits mediate the reinforcement-related signals of striatal cholinergic interneurons. Nat Neurosci, in press.

Figueredo-Cardenas G, Morello M, Sancesario G, Bernardi G, Reiner A (1996) Colocalization of somatostatin, neuropeptide $Y$, neuronal nitric oxide synthase and NADPH-diaphorase in striatal interneurons in rats. Brain Res 735:317-324.

Franklin KBJ, Paxinos G (2008) The mouse brain in stereotaxic coordinates, Ed 3. New York: Academic.

Freund TF, Buzsáki G (1996) Interneurons of the hippocampus. Hippocampus 6:347-470.

Fuentealba P, Begum R, Capogna M, Jinno S, Márton LF, Csicsvari J, Thomson A, Somogyi P, Klausberger T (2008) Ivy cells: a population of nitric-oxideproducing, slow-spiking GABAergic neurons and their involvement in hippocampal network activity. Neuron 57:917-929.

Galarraga E, Vilchis C, Tkatch T, Salgado H, Tecuapetla F, Perez-Rosello T, Perez-Garci E, Hernandez-Echeagaray E, Surmeier DJ, Bargas J (2007) Somatostatinergic modulation of firing pattern and calcium-activated potassium currents in medium spiny neostriatal neurons. Neuroscience 146:537-554.

Gerfen CR, Wilson CJ (1996) The basal ganglia. In: Handbook of chemical neuroanatomy, Ed 12 (Swanson LW, Bjorklund A, Hokfelt T, eds), pp 371-468. Amsterdam: Elsevier Science.

Gittis AH, Nelson AB, Thwin MT, Palop JJ, Kreitzer AC (2010) Distinct roles of GABAergic interneurons in the regulation of striatal output pathways. J Neurosci 30:2223-2234.

Gong S, Zheng C, Doughty ML, Losos K, Didkovsky N, Schambra UB, Nowak NJ, Joyner A, Leblanc G, Hatten ME, Heintz N (2003) A gene expression atlas of the central nervous system based on bacterial artificial chromosomes. Nature 425:917-925.

Graveland GA, DiFiglia M (1985) The frequency and distribution of medium-sized neurons with indented nuclei in the primate and rodent neostriatum. Brain Res 327:307-311.

Ibáñez-Sandoval O, Tecuapetla F, Unal B, Shah F, Koós T, Tepper JM (2010) Electrophysiological and morphological characteristics and synaptic connectivity of tyrosine hydroxylase-expressing neurons in adult mouse striatum. J Neurosci 30:6999-7016.

Karagiannis A, Gallopin T, Dávid C, Battaglia D, Geoffroy H, Rossier J, Hillman EM, Staiger JF, Cauli B (2009) Classification of NPY-expressing neocortical interneurons. J Neurosci 29:3642-3659.

Karayannis T, Elfant D, Huerta-Ocampo I, Teki S, Scott RS, Rusakov DA, Jones MV, Capogna M (2010) Slow GABA transient and receptor desensitization shape synaptic responses evoked by hippocampal neurogliaform cells. J Neurosci 30:9898-9909.

Kawaguchi Y (1993) Physiological, morphological, and histochemical characterization of three classes of interneurons in rat neostriatum. J Neurosci 13:4908-4923.

Kawaguchi Y, Kubota Y (1993) Correlation of physiological subgroupings of nonpyramidal cells with parvalbumin- and calbindinD28k- immunoreactive neurons in layer $\mathrm{V}$ of rat frontal cortex. J Neurophysiol 70:387-396.

Kawaguchi Y, Wilson CJ, Emson PC (1989) Intracellular recording of identified neostriatal patch and matrix spiny cells in a slice preparation preserving cortical inputs. J Neurophysiol 62:1052-1068.

Kawaguchi Y, Wilson CJ, Augood SJ, Emson PC (1995) Striatal interneurones: chemical, physiological and morphological characterization. Trends Neurosci 18:527-535.

Kitai ST, Surmeier DJ (1993) Cholinergic and dopaminergic modulation of potassium conductances in neostriatal neurons. Adv Neurol 60:40-52.

Klausberger T, Somogyi P (2008) Neuronal diversity and temporal dynamics: the unity of hippocampal circuit operations. Science 321:53-57.

Koós T, Tepper JM (1999) Inhibitory control of neostriatal projection neurons by GABAergic interneurons. Nat Neurosci 2:467-472.

Koós T, Tepper JM (2002) Dual cholinergic control of fast-spiking interneurons in the neostriatum. J Neurosci 22:529-535.

Koós T, Tepper JM, Wilson CJ (2004) Comparison of IPSCs evoked by spiny and fast-spiking neurons in the neostriatum. J Neurosci 24:7916-7922.

Kubota Y, Kawaguchi Y (2000) Dependence of GABAergic synaptic areas on the interneuron type and target size. J Neurosci 20:375-386.

Larsson E, Lindvall O, Kokaia Z (2001) Stereological assessment of vulnerability of immunocytochemically identified striatal and hippocampal neurons after global cerebral ischemia in rats. Brain Res 913:117-132.

Lopez-Huerta VG, Tecuapetla F, Guzman JN, Bargas J, Galarraga E (2008) Presynaptic modulation by somatostatin in the neostriatum. Neurochem Res 33:1452-1458.

Nishi K, Atkins PT, Surmeier DJ, Kitai ST (1990) Muscarinic regulation of cyclic AMP metabolism in rat neostriatal cultures. Brain Res 534:111-116.

Oorschot DE (1996) Total number of neurons in the neostriatal, pallidal, subthalamic, and substantia nigral nuclei of the rat basal ganglia: a stereological study using the cavalieri and optical disector methods. J Comp Neurol 366:580-599.

Partridge JG, Janssen MJ, Chou DY, Abe K, Zukowska Z, Vicini S (2009) Excitatory and inhibitory synapses in neuropeptide $\mathrm{Y}$-expressing striatal interneurons. J Neurophysiol 102:3038-3045.

Pearce RA (1993) Physiological evidence for two distinct $\mathrm{GABA}_{\mathrm{A}}$ responses in rat hippocampus. Neuron 10:189-200.

Peterson DA, Dickinson-Anson HA, Leppert JT, Lee KF, Gage FH (1999) Central neuronal loss and behavioral impairment in mice lacking neurotrophin receptor p75. J Comp Neurol 404:1-20.

Planert H, Szydlowski SN, Hjorth JJ, Grillner S, Silberberg G (2010) Dynamics of synaptic transmission between fast-spiking interneurons and striatal projection neurons of the direct and indirect pathways. J Neurosci 30:3499-3507.

Povysheva NV, Zaitsev AV, Kröner S, Krimer OA, Rotaru DC, GonzalezBurgos G, Lewis DA, Krimer LS (2007) Electrophysiological differences between neurogliaform cells from monkey and rat prefrontal cortex. J Neurophysiol 97:1030-1039.

Price CJ, Cauli B, Kovacs ER, Kulik A, Lambolez B, Shigemoto R, Capogna M (2005) Neurogliaform neurons form a novel inhibitory network in the hippocampal CA1 area. J Neurosci 25:6775-6786.

Rushlow W, Flumerfelt BA, Naus CC (1995) Colocalization of somatostatin, neuropeptide $\mathrm{Y}$, and NADPH-diaphorase in the caudate-putamen of the rat. J Comp Neurol 351:499-508.

Rymar VV, Sasseville R, Luk KC, Sadikot AF (2004) Neurogenesis and stereological morphometry of calretinin-immunoreactive GABAergic interneurons of the neostriatum. J Comp Neurol 469:325-339.

Szabadics J, Tamás G, Soltesz I (2007) Different transmitter transients underlie presynaptic cell type specificity of $\mathrm{GABA}_{\mathrm{A}}$, slow and $\mathrm{GABA}_{\mathrm{A}}$, fast. Proc Natl Acad Sci U S A 104:14831-14836.

Tamás G, Lorincz A, Simon A, Szabadics J (2003) Identified sources and targets of slow inhibition in the neocortex. Science 299:1902-1905.

Taverna S, Canciani B, Pennartz CM (2007) Membrane properties and synaptic connectivity of fast-spiking interneurons in rat ventral striatum. Brain Res 1152:49-56.

Tecuapetla F, Koós T, Tepper JM, Kabbani N, Yeckel MF (2009) Differential dopaminergic modulation of neostriatal synaptic connections of striatopallidal axon collaterals. J Neurosci 29:8977-8990.

Tepper JM, Bolam JP (2004) Functional diversity and specificity of neostriatal interneurons. Curr Opin Neurobiol 14:685-692.

Tepper JM, Koós T, Wilson CJ (2004) GABAergic microcircuits in the neostriatum. Trends Neurosci 27:662-669. 
Tepper JM, Wilson CJ, Koós T (2008) Feedforward and feedback inhibition in neostriatal GABAergic spiny neurons. Brain Res Rev 58:272-281.

Tepper JM, Tecuapetla F, Koós T, Ibáñez-Sandoval O (2010) Heterogeneity and diversity of striatal GABAergic interneurons. Front Neuroanat 4:150.

Tricoire L, Pelkey KA, Daw MI, Sousa VH, Miyoshi G, Jeffries B, Cauli B, Fishell G, McBain CJ (2010) Common origins of hippocampal ivy and nitric oxide synthase expressing neurogliaform cells. J Neurosci 30:2165-2176.

Tunstall MJ, Oorschot DE, Kean A, Wickens JR (2002) Inhibitory interactions between spiny projection neurons in the rat striatum. J Neurophysiol 88:1263-1269.

Unal B, Ibáñez-Sandoval O, Shah F, Abercrombie ED, Tepper JM (2011) Distribution of striatal tyrosine-hydroxylase expressing interneurons with respect to anatomical organization of the striatum. Front Syst Neurosci 5:41.

Vilchis C, Bargas J, Pérez-Roselló T, Salgado H, Galarraga E (2002) Soma- tostatin modulates $\mathrm{Ca}^{2+}$ currents in neostriatal neurons. Neuroscience 109:555-567.

Vuillet J, Kerkerian L, Kachidian P, Bosler O, Nieoullon A (1989) Ultrastructural correlates of functional relationships between nigral dopaminergic or cortical afferent fibers and neuropeptide $\mathrm{Y}$-containing neurons in the rat striatum. Neurosci Lett 100:99-104.

Wilson CJ (1993) The generation of natural firing patterns in neostriatal neurons. Prog Brain Res 99:277-297.

Wilson CJ, Kawaguchi Y (1996) The origins of two-state spontaneous membrane potential fluctuations of neostriatal spiny neurons. J Neurosci 16:2397-2410.

Wu Y, Parent A (2000) Striatal interneurons expressing calretinin, parvalbumin or NADPH-diaphorase: a comparative study in the rat, monkey and human. Brain Res 863:182-191.

Xu X, Roby KD, Callaway EM (2010) Immunochemical characterization of inhibitory mouse cortical neurons: three chemically distinct classes of inhibitory cells. J Comp Neurol 518:389-404. 